\title{
A rapid and sensitive method to assess seed longevity through accelerated aging in an invasive plant species
}

\author{
Erola Fenollosa* (1), Laia Jené and Sergi Munné-Bosch (1)
}

\begin{abstract}
Background: Seed longevity and vigor assessment is crucial for efficient ex situ biodiversity conservation in genebanks but may also have potential applications for the understanding of ecological processes and in situ biodiversity conservation. In fact, one of the factors determining the persistence of invasive species, a main threat to global biodiversity, is the generation of soil seed banks where seeds may remain viable for several years. Artificial seed aging tests using high temperatures and high relative humidity have been described for seed longevity estimation but have been mainly optimized for species with commercial interest. Thus, the aim of the study is to define a rapid and sensitive method to assess seed longevity and vigor through accelerated aging in the worldwide distributed invasive species Carpobrotus edulis to provide tools to biodiversity managers to evaluate invasive potential and develop effective post-eradication plans.
\end{abstract}

Results: Slow seed deterioration rate was obtained when C. edulis seeds were subjected to common accelerated aging temperatures $\left(43-45^{\circ} \mathrm{C}\right.$ ). This contrasts with the rapid viability decay between $24-72 \mathrm{~h}$ when seeds were subjected to temperatures superior to $55^{\circ} \mathrm{C}$, a strong inflection point for this species' thermosensitivity. Relative humidity also played a role in defining seed survival curves, but only at high temperatures, speeding up the deterioration process. The selected aging conditions, $55^{\circ} \mathrm{C}$ at $87 \%$ relative humidity were tested over two C. edulis populations and three measures were proposed to parametrize the differential sigmoidal seed survival curves, defining the seed resistance to deterioration $\left(L_{5}\right.$, aging time where $95 \%$ of seeds maintain their viability), medium longevity $\left(L_{50}, 50 \%\right.$ of seeds lose their viability) and lethal aging time ( $\mathrm{L}_{95}, 95 \%$ of viability loss).

Conclusions: An accelerated aging test at $55^{\circ} \mathrm{C}$ and $87 \%$ relative humidity constitutes a rapid and sensitive method that can be performed within a working week, allowing managers to easily test seed vigor and longevity. This test may contribute to assess invasive potential, design effective monitoring programs and soil seed bank eradication treatments.

Keywords: Aizoaceae, Deterioration, Germination, Management, Post-eradication, Seed survival curve, Soil seed bank, Solarization, Temperature, Thermotolerance

*Correspondence: efenollosa@ub.edu

Department of Evolutionary Biology, Ecology and Environmental Sciences, and Institute of Research in Biodiversity (IRBio), University of Barcelona, Barcelona, Spain

\section{Background}

Seed longevity is described as the period over which a seed remains viable and capable of germination [1]. The length of time during which seeds maintain their viability and vigor is a trait of interest not only for crop species within breeding programs and food security, but also for describing natural populations' dynamics and assess 
persistence potential [2-4]. Seed longevity is strongly variable, ranging from just a few months in soybean [5], to more than 2000 years in Phoenix dactylifera [6]. In species with orthodox seeds, viable seeds may enter dormancy, a temporal suppression of germination under favorable conditions, thanks to their ability to tolerate considerable desiccation [7]. The slow pace of seed viability loss in orthodox species hinders the study and characterization of species' seed longevity under natural conditions. Due to those difficulties, ex situ aging tests are used to estimate seed longevity and vigor [8]. Genetic factors have a key influence on seed persistence and because of this, the survival of seeds experiencing moisture and temperature stress in the laboratory is thought to be a good predictor of their potential persistence in the environment [1]. In fact, similar molecular events were found to accompany artificial and natural seed aging processes [9]. Long et al. [10] successfully predicted species seed persistence in the field with the species ranking of the days taken for seed viability to decline by $50 \%$ in an artificial aging test. A faster viability decay under artificial aging conditions is linked to a germination depression with time [11]. There are different proposed approaches to estimate and contrast seed longevity by generating an atmosphere that speeds up the aging process: accelerated aging and controlled deterioration. Controlled deterioration tests were first developed to identify low vigor seeds [12] and consist of subjecting to high temperatures (around $40-45{ }^{\circ} \mathrm{C}$ ) prearranged high seed moisture content (from 18 to $24 \%$ ) for 24 to $96 \mathrm{~h}$ [13]. In contrast, accelerated aging (AA) tests consist of exposing seeds to high temperatures around $40-45^{\circ} \mathrm{C}$ over water, generating an atmosphere with high relative humidity (RH). The AA test was first developed by Delouche and Baskin [14] to estimate the longevity of seeds stored in a warehouse, as the decline in germination following AA is proportional to the initial physiological potential of the seed lot. Seed lots with high vigor should be able to withstand these stress conditions and will deteriorate at a slower rate than lots with poorer vigor [8]. The AA test is preferable for a rapid method as it does not require initial seed moisture control and equilibration, which may suppose extra time and offers similar results to the controlled deterioration test [13].

Standard AA conditions proposed for several crop seeds varies between 41 and $43{ }^{\circ} \mathrm{C}$ for 48 to $72 \mathrm{~h}$ [15]. However, even within a species, seed longevity in AA tests may depend on several factors such as moisture content, $\mathrm{RH}$, oxygen partial pressure and temperature [16]. Higher temperatures and high RH are known to boost seed viability loss [11] but may have different effects in different species. Artificially aged seeds of rice lose their viability between 25 to 45 days at $40{ }^{\circ} \mathrm{C}$ and $80 \%$ of $\mathrm{RH}$ but just in 6 days at $45^{\circ} \mathrm{C}$ and $100 \% \mathrm{RH}$, whereas Arabidopsis thaliana seeds lose their viability within 3 days at $37{ }^{\circ} \mathrm{C}$ at $83 \% \mathrm{RH}$ [8]. Artificially aging protocols have been mainly designed for grain, vegetable, forage, and forestry crops [17] such as rice, wheat, soybean and tomato, leaving aside other species with ecological interest that could offer new insights into seed longevity regulation and over which an optimized AA test could be beneficial to assess ecological dynamics [2]. Artificial aging tests may be useful to test seed lot status and predict when the seeds may reach the viability threshold that may require further actions to conserve the species' germplasm [18], thus improving genebanks' management for ex situ germplasm conservation [19]. Non-crop species' germplasm conservation may be important for maintaining biodiversity's option value (i.e. the value of potential future benefits that are unknown today, such as finding new pharmacologically-beneficial substances), in spite of the difficulties of defining this concept [20-22].

Invasive species constitute one of the five major drives of global biodiversity loss [23] and eradication costs increase with invasion time specially for those invaders that are able to generate a permanent soil seed bank [24]. Carpobrotus edulis (L.) N. E. Br. (Aizoaceae) is a mat-forming trailing succulent perennial that has been introduced into all continents, mostly growing in the Mediterranean regions [25]. This species is native from South Africa where it is used in traditional medicine for its several pharmacological applications for the treatment of tuberculosis and other respiratory infections, toothache and earache, facial eczema, wounds, burns, hypertension, and diabetes mellitus, due to the antimicrobial, antiproliferative, and antioxidant properties of C. edulis leaf extracts [26]. Despite its pharmacological potential, in the introduced range, this species impacts native communities by decreasing biodiversity and altering nutrient cycling dynamics $[27,28]$. The production of allelopathic compounds contribute to the drastic modification of this species surroundings inhibiting native species germination [29]. One of the factors determining this invasive species' persistence is the intense flowering and high amount of small hard-coated reniform orthodox seeds produced, which generates a permanent soil seed bank [30]. Invasive species eradication costs are extremely high in advanced invasion stages, especially because local eradication is not possible as long as seeds remain viable in the soil. In weed eradication and control programs it is critical to know the characteristics of the soil seed bank for the implementation of successful control measures and monitoring [31]. Some ex situ techniques have been proposed to predict the persistence of seeds and to enable policy makers to make 
faster and better-informed decisions in weed-management programs [32]. Assessing seed longevity in invasive plants becomes crucial for management policies when prioritizing zones or determining budget allocation in post-eradication plans. Considering C. edulis wide distribution, its ecological impacts and the fact that it is able to generate a permanent soil seed bank that increase eradication costs, we aimed to describe a rapid AA test for the seeds of this invasive species, evaluating the role of different parameters to estimate seed vigor in natural populations. We tested over different natural populations the optimal conditions that generate a progressive viability loss following the sigmoidal response described for seed aging within a short time period (less than 10 days), maximizing feasibility with low economic costs. This test may be useful for management programs to assess invasive potential, define eradication strategies and promote effective genebank management in non-crop species.

\section{Results}

The different experimental conditions tested lead to the understanding of the importance of several factors determining artificial aging seed survival curves in C. edulis. All artificial aging tested conditions lead to a loss in the initial seed viability, but its timing was strongly influenced by the induced conditions. When it comes to keeping the aging environmental stable, some treatments were found more feasible than others, which helped to decide the best artificial aging environment for $C$. edulis seeds in terms of speed, feasibility and simplicity. The final aging protocol (resumed in Fig. 1) was defined at $55^{\circ} \mathrm{C}$ and $87 \% \mathrm{RH}$ and revealed differential seed survival curves between the two tested natural populations.

\section{Temperature}

Temperature strongly influenced seed survival curves and their medium longevity (Fig. 2). The lowest tested temperature $\left(43^{\circ} \mathrm{C}\right)$ led to a constant and unhurried loss of seed viability of only a $20 \%$ loss in 18 days (Fig. 2a). Similar aging pace was observed at 45 and $50{ }^{\circ} \mathrm{C}$ but an

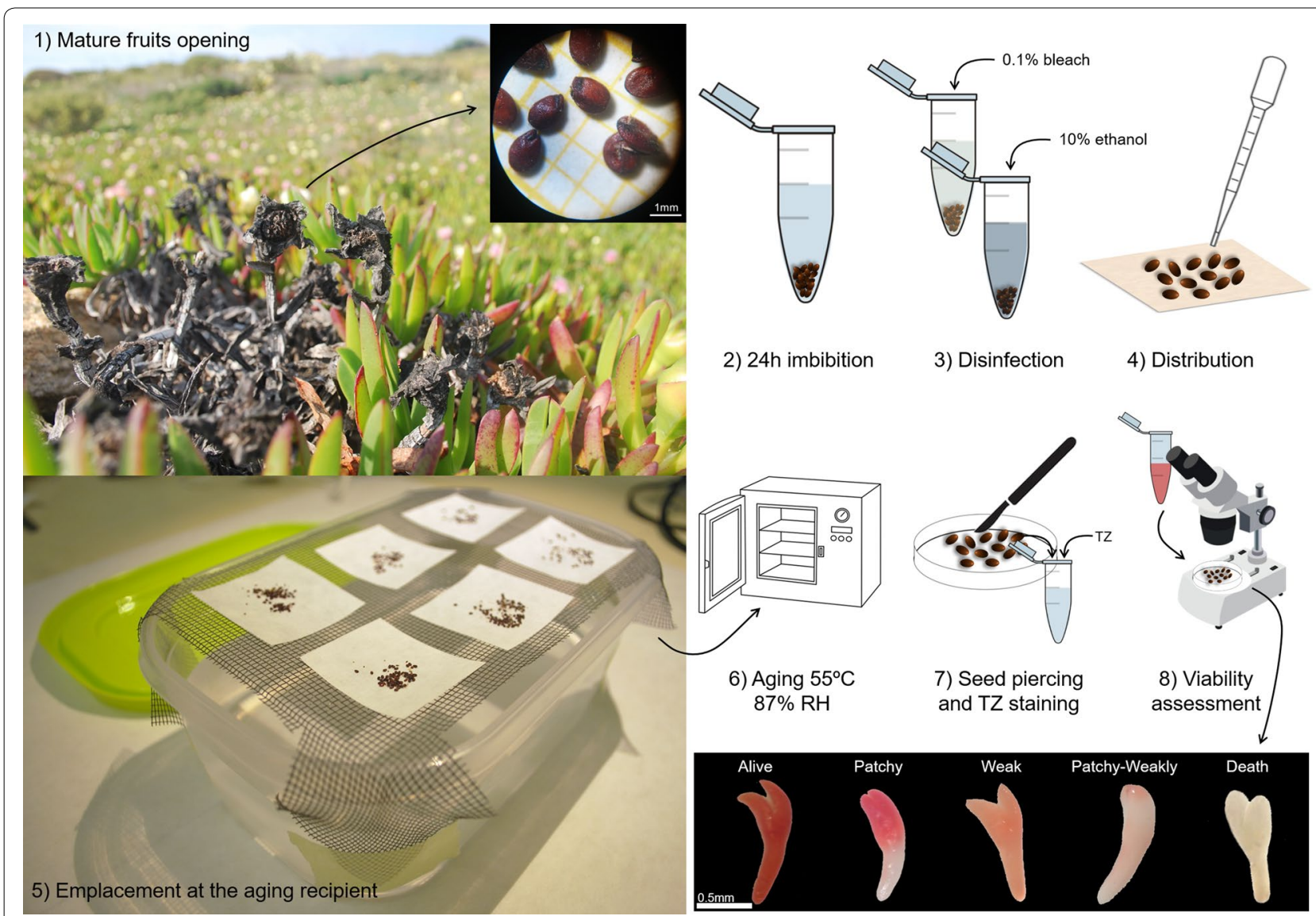

Fig. 1 Eight-step accelerated aging test optimized for C. edulis. Eight steps describing the accelerated aging protocol from seed collection (step 1) to classification of stained C. edulis embryos after tetrazolium (TZ) incubation for viability testing according to the staining intensity and distribution (step 8) 


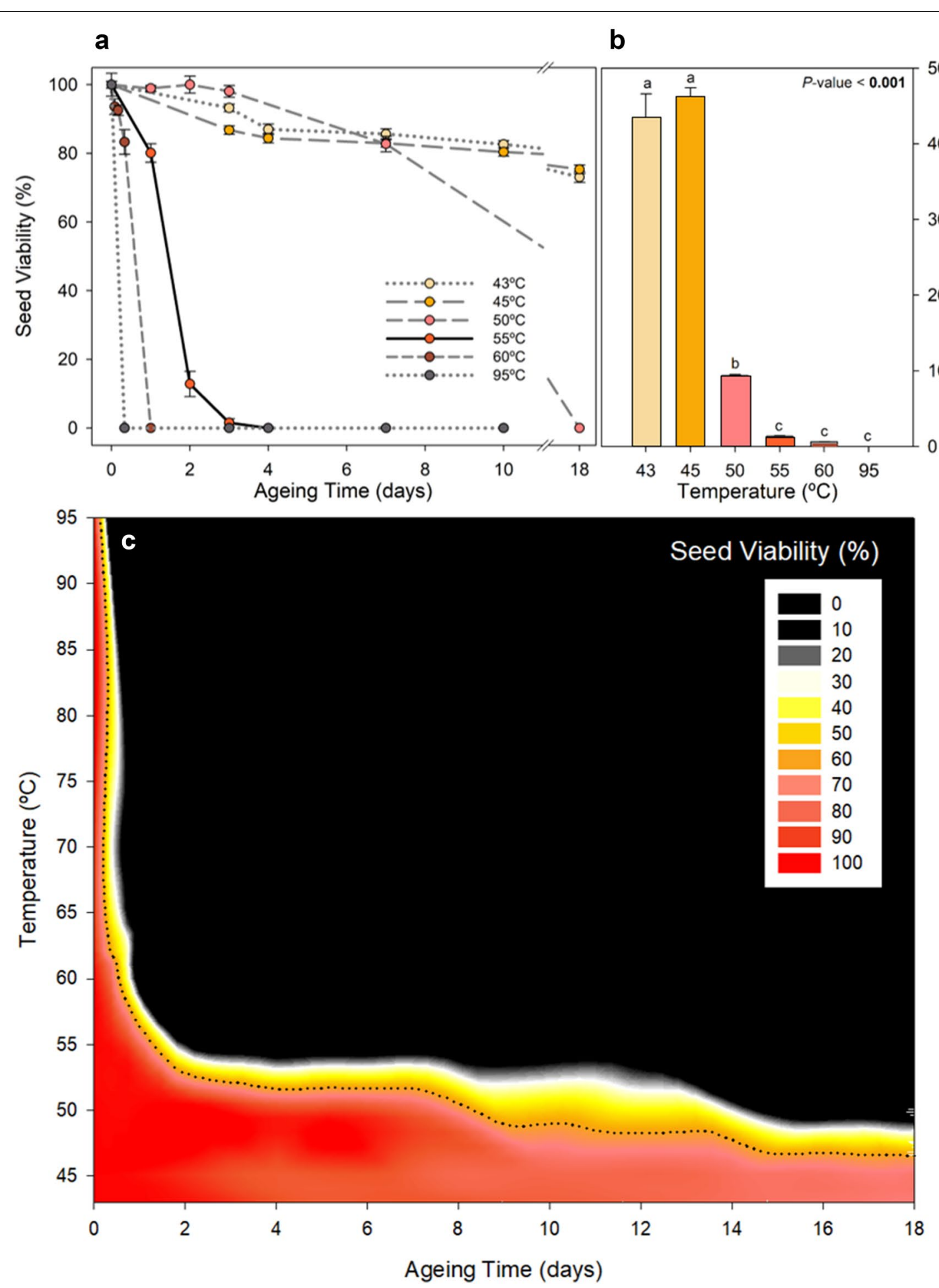

Fig. 2 Influence of temperature and aging time in artificially aged seeds of C. edulis. a Viability loss of C. edulis seeds at the different tested temperatures and $87 \%$ RH. Data is represented as Mean $\pm S E(n=6)$. $\mathbf{b} L_{50}$ (loss of $50 \%$ viability) at the different tested temperatures. Different letters indicate statistically significant differences $(P$-value $<0.05)$. c Contour plot of seed viability considering temperature and aging days. Dotted line represents the $L_{50}, 50 \%$ viability loss 
abrupt change was observed at $55^{\circ} \mathrm{C}$, leading to the typical sigmoidal seed survival curve (Fig. 2a). Higher temperatures induced $100 \%$ viability loss between 3 and $24 \mathrm{~h}$ under $60^{\circ} \mathrm{C}$ and less than $3 \mathrm{~h}$ under $95^{\circ} \mathrm{C}$ (Fig. 2a). Those temperatures led to the apparition of burned embryos with brownish coloration. The $\mathrm{L}_{50}$, the time required to reach a $50 \%$ viability loss decreased sharply with increasing temperatures, from around 45 days under $43-45^{\circ} \mathrm{C}$ to just a few hours at $60{ }^{\circ} \mathrm{C}$ (Fig. 2b). Temperatures above $55^{\circ} \mathrm{C}$ may offer artificial aging intervals within a week, as $L_{50}$ was found between 2 and 3 days of aging treatment. Seed viability did not decrease linearly with temperature and aging time, instead, a strong inflection point was observed around $55^{\circ} \mathrm{C}$ when contrasting aging time, temperature and seed viability (Fig. 2c).

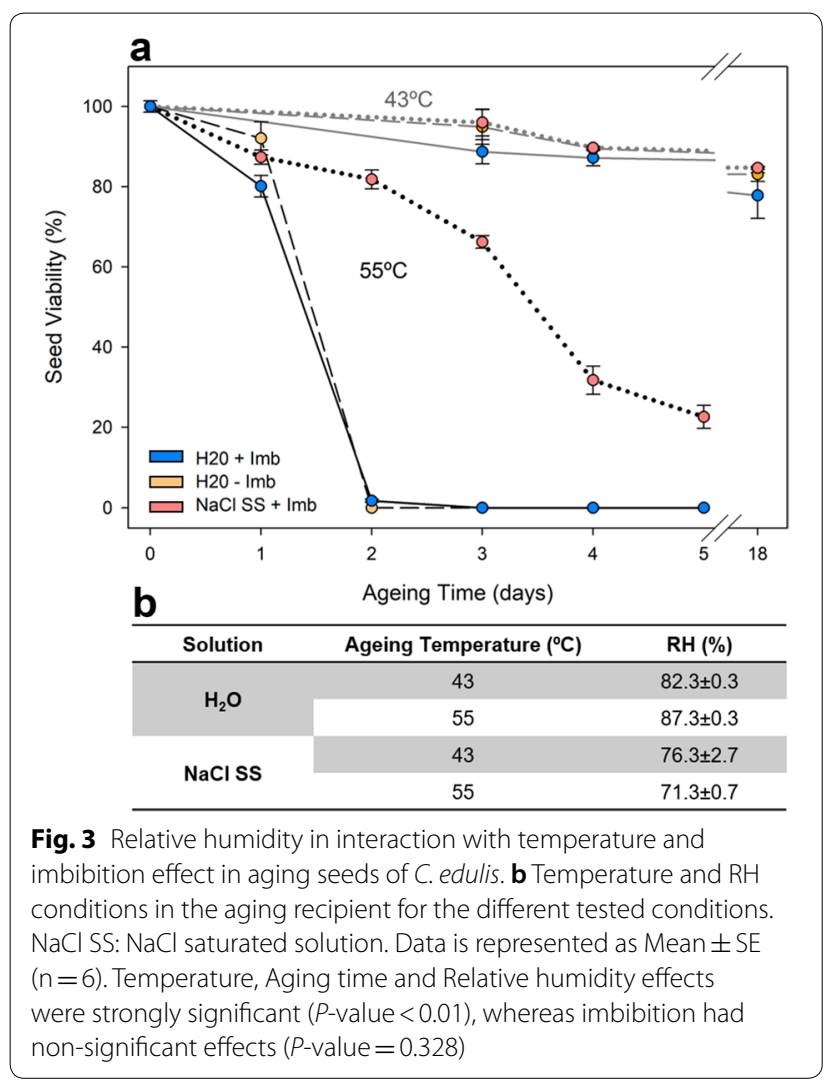

\section{Relative humidity and seed imbibition}

The amount of water vapor in the aging atmosphere determined differences in seed survival curves. The superior $\mathrm{RH}$ obtained in the $82-87 \% \mathrm{RH}$ experiment (using distilled water) determined an accelerated viability loss in contrast with the $71-76 \% \mathrm{RH}$ experiment (using a saturated salt solution, $\mathrm{NaCl}$ ) (Fig. 3). This difference was observed under $55{ }^{\circ} \mathrm{C}$ but not at $43{ }^{\circ} \mathrm{C}$, where no differences in the seed survival curve were observed (Fig. 3).
When contrasting treatments at $55{ }^{\circ} \mathrm{C}$, high $\mathrm{RH}(87 \%)$ lead to a complete viability loss after two aging days, whereas a lower humidity (71\%) triggered a progressive viability loss that leave $20 \%$ viable seeds after five aging days (Fig. 3). Apart from a different seed survival curve, the imbibed seeds in low $\mathrm{RH}$ conditions $(71 \%)$ at $55{ }^{\circ} \mathrm{C}$ were found with a hardened seed coat at all aging times, hindering seed piercing for viability analysis.

Seed imbibition did not exert any significant effect on seed survival curve at any aging time when compared with non-disinfected dry seeds (Fig. 3a). However, clear practical benefits were found when placing seeds on the aging container with water using a Pasteur pipet, instead of placing them one by one in dry with tweezers. In spite of the fact that imbibed seeds and non-disinfected dry seeds showed no significant differences within the viability loss interval $(0-120 \mathrm{~h})$, the lack of seed disinfection promoted fungus attacks from the 7th aging day in some replicates, which contributed to discard this treatment.

\section{Viability and germination's potential loss}

The seed survival curves in terms of viability and germination tested in the two different populations of C. edulis triggered two differentiated responses. Initial seed moisture content was not significantly different $(P$-value $>0.05)$ between the two populations: with $13.54 \pm 0.82 \%$ and $14.22 \pm 0.64 \%$ in population 1 and population 2 respectively. Population 1 followed a sigmoidal pattern with an abrupt fall within the 40 and 80 aging hours range, whereas population 2 showed a slow viability loss without a resistance phase (Fig. 4). Initial viability was found very high (around 70-90\%), whereas initial germination percentage fell to $20 \%$ in Population 2. The viability loss was accompanied by an increase in the proportion of dying seeds in both populations (patchy and patchy-weakly embryos, Fig. 4b). Those dying seeds were unable to germinate as shown by the null germination rates found after 72 aging hours (Fig. 4c). Germination time was initially similar between the two populations and maintained at 40 days until 24 aging hours. Whereas population 1 maintained mean germination time after 48 aging hours, population 2 showed a significant decay at this time. Similarly, a strong decrease in the mean germination rate was observed past the 48 aging hours (Fig. 4).

\section{Seed longevity estimation}

A non-linear response was found for viability loss with aging time (Fig. 4a). The best fit for the sigmoidal curve of the seed survival was observed using Weibull model adjustment. This model allowed the estimation of different parameters (Fig. 4a). The best fitted viability loss for population 1 was a Weibull type 2 with three parameters: 


$$
V=83.06\left(1-e^{-e^{-9.3(\log (x)-\log (52.33))}}\right)
$$

Whereas the best-fitted viability loss for population 2 was a Weibull type 1 with three parameters:

$$
V=72.64 e^{\left(-e^{1.65(\log (x)-\log (40.61)}\right)}
$$

where $\mathrm{V}$ stands for Viability (\%), and $\mathrm{x}$ for aging time in hours. To characterize seed survival curve we propose the use of three different parameters that reflect: aging resistance $\left(\mathrm{L}_{5}\right)$, mean longevity $\left(\mathrm{L}_{50}\right)$ and lethal aging time $\left(\mathrm{L}_{95}\right)$ under aging conditions, that define the number of hours to achieve 5, 50 and $95 \%$ of viability loss respectively. Those parameters characterize the two differentiated seed survival curves obtained for the two natural populations. The lack of seed resistance to aging conditions of population 2 was reflected in the small $\mathrm{L}_{5}(6.73 \pm 1.25 \mathrm{~h})$ in comparison with population 1 (46.51 \pm 0.80 h) (Fig. 4). Moreover, different $\mathrm{L}_{50}$ reflected the medium seed longevity that also differed between populations and was found between 32 and 54 aging hours. Lethal aging time $\left(\mathrm{L}_{95}\right)$ was found past the 72-79 aging hours in both populations.

\section{Discussion}

\section{Seed resistance to temperature and relative humidity}

Temperature played the most important role in reducing seed longevity in $C$. edulis. Increasing temperatures are described to reduce the accelerated aging time, with seeds reaching the $0 \%$ viability in a shorter time [11]. Substantial decrease in the activity of antioxidants in response to increased accumulation of reactive oxygen species is associated with accelerated aging [33-36]. If not counterbalanced, reactive oxygen species lead to the accumulation of damaged molecules such as lipid hydroperoxides and protein carbonylation that increase strongly in deteriorating seeds and may ultimately lead to seed death $[37,38]$. Seeds may respond to high temperatures with seed death (non-tolerant seeds), non-altered viability (tolerant seeds) or trigger increased germination (i.e. pyrophile plants) [39, 40]. Seed survival curves may vary depending on specific temperature and exposure time [41]. In the case of C. edulis, $5{ }^{\circ} \mathrm{C}$ increase from 45 to $50{ }^{\circ} \mathrm{C}$ were enough to reduce 4 times the $\mathrm{L}_{50}$, suggesting a strong sensitivity to temperature. Moreover, C. edulis seeds did not tolerate $3 \mathrm{~h}$ exposure at $95{ }^{\circ} \mathrm{C}$ as other Aizoaceaceae may do according to the study developed

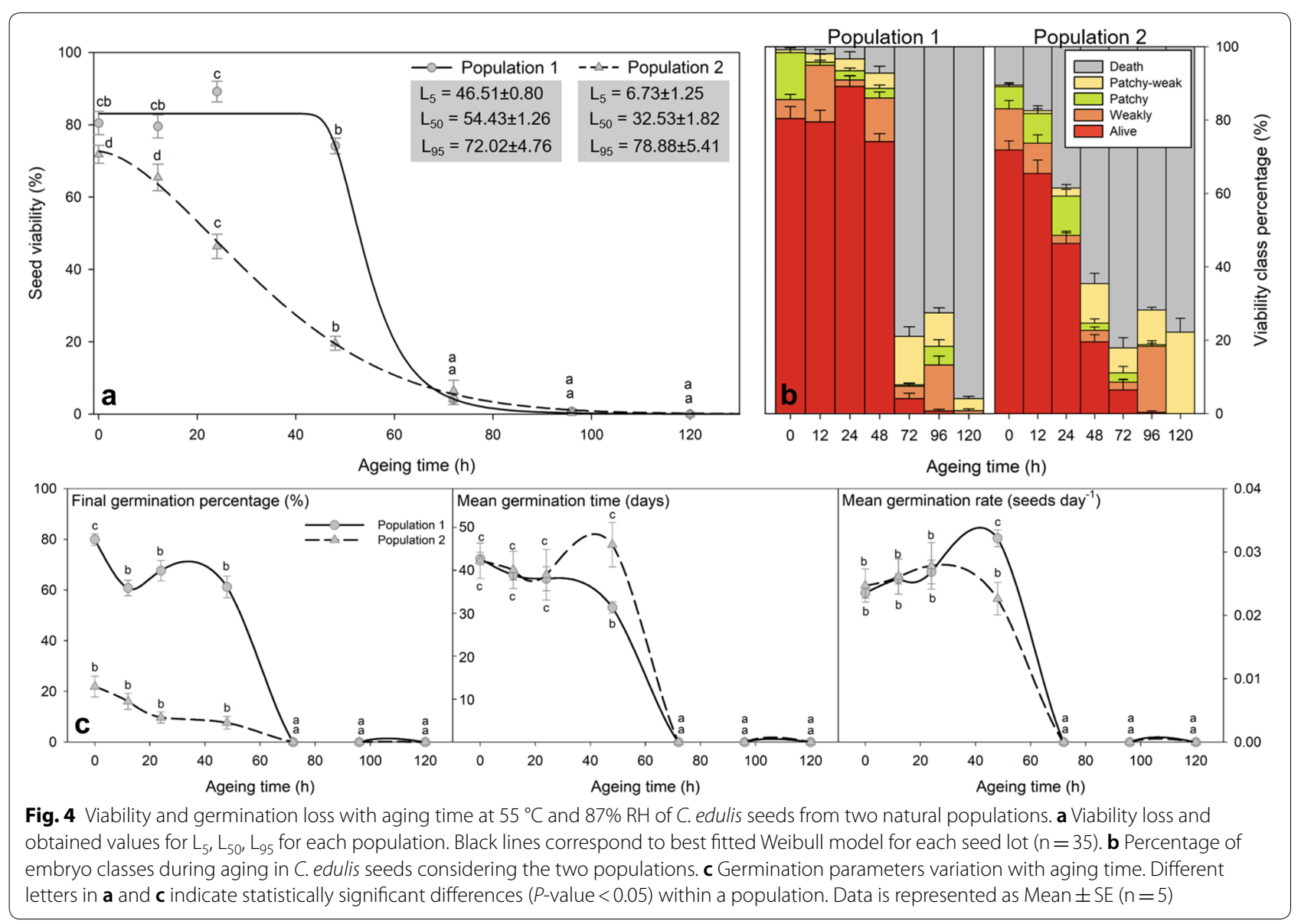


by Daws et al. [42], where at least $20 \%$ seed survival was observed in 26 Aizoaceae species at $103^{\circ} \mathrm{C}$ for $17 \mathrm{~h}$. Seeds of Welwitschia mirabilis from the Namib Desert have been reported to tolerate $80{ }^{\circ} \mathrm{C}$ for $48 \mathrm{~h}$ [43]. However, those studies were orientated to evaluate seeds thermotolerance and low RH was used. High RH (up to 75-80\%) is recommended for testing seed longevity [8]. Differences in $\mathrm{RH}$ generate differential seed survival curves in C. edulis seeds under sensitive temperatures, with higher RH $(87 \%)$ promoting a faster seed aging in comparison with lower RH $(73 \%)$. This result coincides with those obtained in Jatropha curcas L. seeds, which showed a faster deterioration in AA tests over water in contrast with using a saturated salt solution [44]. Similar results were obtained with Hirschfeldia incana when comparing humid $(75 \%)$ and dry $(33 \% \mathrm{RH})$ storage at $35{ }^{\circ} \mathrm{C}$, where humid storage decreased almost 100 times seed longevity [45]. In fact, resultant products of non-enzymatic modifications of protein structures through glycation found in accelerated aged soybean seeds were formed most rapidly in seeds at high humidity [46]. The inactivation of proteins would depress the metabolic capacity and reduce the ability of biological systems to repair cellular damage occurring during storage [47].

When contrasting aging tolerance of $C$. edulis seeds with conventional artificial aging protocols for commercial seeds, $C$. edulis appears to have an increased tolerance. Considering that the general temperature for artificial aging is between 41 and $43{ }^{\circ} \mathrm{C}$ for 48 to $72 \mathrm{~h}$ [8, 15], C. edulis seeds may be considered resistant, as under those temperatures, viability was maintained above $80 \%$ at least for 10 days. Moreover, $80 \%$ of $C$. edulis seeds survived after a heat shock of $3 \mathrm{~h}$ at $60{ }^{\circ} \mathrm{C}$, whereas imbibed seeds from other species may not even survive a 30-min shock at this temperature [48]. Ex-situ seed longevity was found to be correlated with drought exposure during the post-zygotic phase in dry and warm environments using 16 closely-related populations of the genus Silene [49]. Post-zygotic C. edulis phase occurs during summer, coinciding with low water availability and the highest yearly temperatures, [50] which may contribute to explain increased ex situ seed longevity in comparison with other commercial species subjected to similar AA tests.

\section{Optimal conditions for artificial aging and measurement of seed longevity}

The optimal conditions for AA test in C. edulis were selected considering speediness, simplicity and sensitivity. The chosen conditions for artificial seed aging were $55^{\circ} \mathrm{C}$ over water $(87 \% \mathrm{RH})$ using imbibed $C$. edulis seeds. The chosen temperature and relative humidity offer the possibility to test seed longevity within a week, as longevity is lost in $3-5$ days. Moreover, $55{ }^{\circ} \mathrm{C}$ constitutes the inflection point in the viability loss-aging time curve suggesting high sensitivity to changes in seed longevity at this temperature. Besides the advantageous temporal scale of using $55^{\circ} \mathrm{C}$ and a water solution, it also requires less preparation than using a saturated salt solution and avoids the risk of salt crystallization over seeds. Finally, seed imbibition and disinfection did not lead to any significant difference and offered substantial practical benefits as seed softening, disinfection facilities and seed disposal in the aging containers pipetting seeds instead of nipping them one by one.

Seed survival curve typically shows a lag phase before seed viability starts to decline rapidly [8]. This was the observed response for $C$. edulis seeds to selected artificial aging conditions, in both the analysis of seed viability (which took two working days in a 3 days' time interval) and seed germination (which took 70 days of germination control every 3 days) coinciding in duration of the lag phase and survival loss in the two C. edulis populations. Viability measures may be equally accurate and may be less time-consuming than germination measurements, as also exposed in $\mathrm{Xu}$ et al. [51]. Although both populations showed similar seed viability (around 70-80\%), population 2 showed a $25 \%$ germination, revealing that $45 \%$ of viable seeds did not germinate, which may correspond to dormant seeds. Viability test is also preferable in comparison to germination test as it reflects seed lot viability regardless of their dormant state [52]. The characterization of the tipping point in the modeled sigmoidal curve of viability loss before the sharp decline is essential, corresponding to exhaustion after the resistance phase in seed stress responses, characterized by a failure of protection and repair and critical cell death [53]. To characterize the duration of the resistance phase, $\mathrm{L}_{5}$ (the aging time when $95 \%$ of the initial viable seeds remain viable) is here proposed. Company et al. [4] have proposed $\mathrm{P}_{20}$ (the aging time to decrease a $20 \%$ seed survival) to characterize the first survival loss in the curve but this measure may fall very close to the $\mathrm{L}_{50}$ and will not provide new information. The aging time that causes a 50\% decrease in seed survival has been largely accepted as a measure of seed longevity [8]. Besides this measurement, the point where seeds no longer germinate $\left(\mathrm{P}_{0}\right)$ was proposed by Dowsett et al. [2] to be a better measurement of seed longevity due to the rapid decline in germination. In this way, Company et al. [4] also proposed the use of $\mathrm{P}_{80}(80 \%$ of seed mortality). We suggest that $\mathrm{L}_{95}$ (the point where only $5 \%$ viability is observed) may be a better indication of the lethal seed aging time when estimating parameters from a fitted curve. The triplet of parameters: $\mathrm{L}_{5}, \mathrm{~L}_{50}$ and $L_{95}$ may provide information on sensitivity, medium aging time, and maximum resistance of a seed lot. 


\section{Artificial aging to assess invasive potential}

Dowsett et al. [2] suggested that artificial aging tests may have a valuable role in understanding the biology of weed species. Besides understanding their biology, artificial aging tests may contribute to design effective management policies and eradication strategies. Recently, Company et al. [4] evaluated the potential competitive displacement of the invasive species Cortaderia selloana over the native Saccharum ravennae using seed germination and viability tests under AA conditions and revealed that no long periods of subsequent monitoring are needed after eradication of $C$. selloana, as this species presented low seed longevity. The two C. edulis populations where the AA test was tested showed different seed longevities towards an increased seed vigor in population 1 , that may require increased eradication efforts. Accelerated aging tests on $C$. edulis may allow rapid assessment by managers and policy makers of seed's vigor at different zones and may contribute to design effective monitoring programs taking into account seed longevity estimations with appropriated budget allocation. Moreover, posteradication soil seed bank vigor monitoring may contribute to define re-invasion risks and estimate weed eradication programs [32].

The artificial aging test optimized contributes to the understanding of invasive seed thermosensitivity that may be used to design soil seed bank eradication treatments. In this way, soil solarization is a non-chemical environmentally-friendly agricultural method for soil disinfestation. Using transparent polyethylene sheets, the temperature of the soil at a depth of $0-20 \mathrm{~cm}$ usually reaches $40-60{ }^{\circ} \mathrm{C}$, leading to the eradication of pathogens, arthropod pests, and weeds. This soil treatment has been already tested to manage invasive seed banks and lead to significantly reduced viability of buried Acacia seeds, including the invasive species $A$. saligna, $A$. murrayana and $A$. sclerosperma, by exposing seeds to lethal hydrothermal conditions, constituting an effective method to reduce the persistent invasive seed bank of those species [54-56]. Considering the $C$. edulis seeds' thermic sensitivity described here and the fact that a $77.6 \%$ of this species' soil seed bank is mainly found in the species' litter and the first 0-5 soil cm [30], soil solarization may constitute a promising tool for invaded soil seed bank eradication. Just $24 \mathrm{~h}$ at $60{ }^{\circ} \mathrm{C}$ and $87 \%$ RH may be enough to obtain a complete viability loss in $C$. edulis seeds. Midday soil surface temperatures in the range $50-80{ }^{\circ} \mathrm{C}$ have been reported in environments ranging from tropical forests to deserts $[57,58]$, and $60^{\circ} \mathrm{C}$ may be easily obtained under polyethylene sheets with air temperature reaches $30^{\circ} \mathrm{C}[56]$.
However, further research is needed to determine the effectivity of a soil solarization treatment under natural soil moisture conditions and the effect of thermal cycles versus the sustained temperatures explored here.

\section{Conclusions}

The inflection point found with temperature-aging time analysis led to the definition of a rapid and sensitive method for $C$. edulis seeds artificial aging at $55^{\circ} \mathrm{C}$ under $87 \% \mathrm{RH}$, where viability is lost within a working week, allowing managers to easily test seed vigor and longevity to assess invasive potential and contribute to design effective monitoring programs taking into account seed longevity estimations with appropriated budget allocation at different invaded areas. C. edulis seed thermosensitivity has been addressed suggesting that soil solarization treatments that mimic the described conditions may be effective for this species' soil seed bank eradication. The optimization of artificial aging tests in non-crop species may provide new insights into seed longevity regulation and develop efficient management practices for ex situ germplasm conservation.

\section{Methods}

\section{Plant material}

A first lot of $C$. edulis seeds was selected to test the aging conditions from a natural population growing in Premià de Mar (Spain, 41 $1^{\circ} 29^{\prime} 24.2^{\prime \prime} \mathrm{N} 2^{\circ} 21^{\prime} 49.3^{\prime \prime} \mathrm{E}$ ). Once aging conditions were set, seeds from two natural populations of $C$. edulis were selected because of their large number of individuals and their large seed availability (population 1: $41^{\circ} 28^{\prime} 25.5^{\prime \prime} \mathrm{N} 2^{\circ} 17^{\prime} 54.7^{\prime \prime} \mathrm{E}$; population 2: $41^{\circ} 28^{\prime} 30.3^{\prime \prime}$ $\left.\mathrm{N} 2^{\circ} 18^{\prime} 04.6^{\prime \prime} \mathrm{E}\right)$. These populations were used to test the accelerated aging test. From each population, within the period of natural seed rain, 600 fruits were collected to ensure representativeness. Fruits were opened and all the obtained seeds were pooled (more than 10.000 seeds per population). Seeds were kept at darkness and room temperature until analysis (3-4 weeks). Prior to start the accelerated aging tests, seed moisture content (\%) was measured for both populations as: FW-DW*100/DW, where FW stands for 50 seeds fresh weight and DW for those 50 seeds dry weight (obtained after $72 \mathrm{~h}$ at $70{ }^{\circ} \mathrm{C}$ ) with five replicates. In the two populations, accelerated aging through viability tests and germination was tested as described in the following sections.

\section{Accelerated aging test}

Different containers were tested regarding their surface/ volume ratios to maximize seed disposition and effectivity and preservation of the aging conditions. It was concluded that a commercial polypropylene hermetic 
container of $1.1 \mathrm{~L}$ capacity with a $20 \times 5 \mathrm{~cm}$ surface (PlasticForte, Spain) was ideal to generate a controlled atmosphere that maintains the desired $\mathrm{RH}$ and hold the seeds at a determined point with $70 \%$ of the capacity filled with aging solution (Fig. 1). There was an exception at $95{ }^{\circ} \mathrm{C}$ where due to the temperature, the experiment was performed using glass jars. Five replicates per population, including fifty seeds per replication were used.

The preparation of the aging containers was performed as follows: first, containers and sized meshes were disinfected with $70 \%$ ethanol and filled with $700 \mathrm{ml}$ of aging solutions: water or $\mathrm{NaCl}$ saturated solution (See relative humidity experiment below). Mesh was fixed using masking tape. Seeds were submerged in $0.1 \%$ bleach for $30 \mathrm{~s}$ and $10 \%$ ethanol for $30 \mathrm{~s}$ more and washed multiple times with distilled water. Containers were only opened when the aging treatment ended at the chosen time: from 3 to 18 days. At that moment, seeds were prepared for the viability test as described in the succeeding sections. Zero aging hours corresponds to viability (through tetrazolium viability test) or germination assessment on nonartificially aged seeds for viability and germination tests respectively.

\section{Temperature experiment}

The role of aging temperature, $\mathrm{RH}$ and seed imbibition and disinfection on the seed survival curve in terms of seed viability was tested. The general aging procedures suggest the use of $41-43^{\circ} \mathrm{C}$ in a high humidity environment for a specified duration $(48-72 \mathrm{~h})[8,15]$. However, seeds from some Aizoaceae species are known to resist even higher temperatures for a short period of time [42]. Considering this, aging was tested at the following spectrum temperatures: $43,45,50,55,60,95{ }^{\circ} \mathrm{C}$ using a laboratory oven under high humidity conditions using distilled water aging solution inside the containers that generated an atmosphere of $87 \% \mathrm{RH}$.

\section{Relative humidity and seed imbibition experiment}

To evaluate the role of RH inside the aging container, distilled water and a saturated commercial $\mathrm{NaCl}$ solution (40 g/100 ml $\mathrm{H}_{2} \mathrm{O}$ ) were used. Saturated salt solutions are often used for controlling environmental variables as they generate a defined $\mathrm{RH}$ environment, inferior to a water-saturated atmosphere [44]. Relative humidity and temperature inside the aging container were tested by introducing a data logger sensor (EasyLog, Lascar Electronics) and a wireless digital thermometer and hygrometer (WA10-Kira EU, Oria) after different time intervals (24, 48, 72 and $96 \mathrm{~h}$ inside aging containers).

Seed imbibition is recommended in tetrazolium viability tests (see seed viability section) because it softens the seed coat and activate enzymatic systems [52]. In order to standardize conditions for initial viability measurement and accelerated aging conditions, imbibition was also proposed before accelerated aging. Seed imbibition was performed with distilled water during $24 \mathrm{~h}$ (for its compatibility with the normal laboratory routine) in the dark and at room temperature. Unlike imbibed seeds, dry seeds were not disinfected to maintain the dry conditions and compare the seeds dry original state and the imbibed and disinfected seeds. Using a Pasteur pipette for imbibed and tweezers for dry seeds, seeds were distributed into the $10 \mathrm{~cm}^{2}$ filter paper that was placed on the containers' mesh together with other replicates.

\section{Seed viability}

To asses seed viability at the different aging times, the tetrazolium (triphenyl tetrazolium chloride) test was used $[15,52,59]$. Seeds were delicately pierced under a binocular magnifying glass to ensure tetrazolium penetration. No staining was observed in non-pierced seeds. Five replications per population, including fifty seeds per replication were disposed in $2 \mathrm{ml}$ capacity eppendorfs with $0.5 \mathrm{ml}$ of $0.1 \%$ tetrazolium (Sigma-Aldrich, Steinheim, Germany) and was incubated for $48 \mathrm{~h}$ at $40{ }^{\circ} \mathrm{C}$ before viability assessment (Fig. 1). Tetrazolium incubation conditions were chosen following the recommendations from standard procedures $[15,52,59]$ that suggest higher temperatures (within the defined accuracy range $20-40{ }^{\circ} \mathrm{C}$ ) to speed up the staining process. Tetrazolium staining time was evaluated within the interval described for some species from 2 to $48 \mathrm{~h}[52,59]$ and staining time inferior to $48 \mathrm{~h}$ revealed incomplete stained embryos. After two days, tetrazolium was withdrawn using a $1 \mathrm{ml}$ pipette and $0.5 \mathrm{ml}$ of distilled water was added to each eppendorf to facilitate further seeds displacement. Using a Pasteur pipette, seeds were spread in a petri dish under a binocular magnifying glass and seed viability was assessed using tweezers. A little squeeze was enough to force the embryo to escape the seed coat and determine its vigor. Six different categories were used to classify embryo status: viable (totally stained), weakly (pale stained), patchy (partially stained), patchy-weakly (partially pale stained), death (white embryo), and aborted (no embryo found) (Fig. 1). The sum of weakly, patchy and patchy-weakly seeds constitutes low vigor seeds without survival probabilities (dying). To speed and facilitate data collection, three smart phone free apps were used for voice recording during embryo viability classification (Voice recorder from Splend Apps), afterwards fast reproduction (Music Speed Changer from Single Minded Productions, LLC), and class counting (Thing counter from Karuma). 


\section{Seed germination}

Seed germination was performed as described in Novoa et al. [60] and Podda et al. [61] with brief modifications on artificially aged seeds of populations 1 and 2 for the different aging times $(0,12,24,48,72,96$ and $120 \mathrm{~h}$ ). Different conditions of $\mathrm{pH}$, temperature alternation and acid pre-treatment were tested, obtaining the best results with $12 \mathrm{~h}$ photoperiod with temperature alternation between $25^{\circ} \mathrm{C}$ during the day and $10{ }^{\circ} \mathrm{C}$ at night. Germination was assessed every three days over wet Whatman paper ( $90 \mathrm{~mm}$ No. 1 filter) in petri dishes. Five replications per population, including fifty seeds per replication were used. Final germination percentage was estimated after curve saturation at 70 days. Mean germination time and mean germination rate were estimated using the GerminaR package in R 3.5.0.

\section{Data analysis}

Significant differences between aging time or temperature were tested using a one-way ANOVA, evaluating the effects of the fixed factor 'Aging time' for the different variables in Fig. 4 and the fixed factor 'Temperature' in Fig. 2b using Tukey test to contrast differences between factor levels in R 3.5.0. A four-way ANOVA was used to test the effects of the three fixed factors: 'Relative humidity', 'Temperature', 'Aging time' and 'Imbibition', for the times $0,24,4872,96 \mathrm{~h}$, assuming that viability at $43^{\circ} \mathrm{C}$ after 24 and $48 \mathrm{~h}$ was equal to $72 \mathrm{~h}$ in Fig. 3a. Normality and homoscedasticity were confirmed using the ShapiroWilk and Levene tests respectively. Seed survival curves were fitted using the $d r c \mathrm{R}$ package for dose-response curves fitting that include different adjustments, including Weibull models that can contemplate asymmetrical losses' responses [62]. The best model was selected using the AIC criteria. Longevity parameters $\left(\mathrm{L}_{5}, \mathrm{~L}_{50}\right.$ and $\left.\mathrm{L}_{95}\right)$ were estimated using the ED function from the $d r c \mathrm{R}$ package. SigmaPlot 10.0 (Systat, USA) was used to create the presented plots.

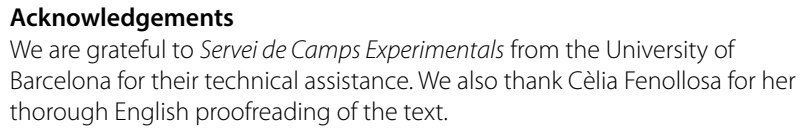

\section{Authors' contributions}

$\mathrm{EF}$ and $\mathrm{SMB}$ conceived the idea and $\mathrm{EF}, \mathrm{LJ}$ and $\mathrm{SMB}$ designed the experimental design. $E F$ and $L J$ performed the experiments and analyzed the obtained data. EF prepared the manuscript. $L J$ and SMB revised the manuscript. All authors read and approved the final manuscript.

\section{Funding}

This research was funded by the Generalitat de Catalunya through the ICREA Academia award given to SMB. EF is a recipient of a FPU fellowship from the Spanish Ministry of Education (FPU 15/06666).

\section{Availability of data and materials}

The datasets used and/or analyzed during the current study are available from the corresponding author on reasonable request.

\section{Ethics approval and consent to participate}

Not applicable.

\section{Consent for publication}

Not applicable.

\section{Competing interests}

The authors declare that they have no competing interests.

Received: 10 March 2020 Accepted: 30 April 2020

Published online: 08 May 2020

\section{References}

1. Bekker RM, Bakker JP, Ozinga WA, Thompson K. Seed traits: essential for understanding seed longevity. Ann Appl Biol. 2003;69(1):1-9.

2. Dowsett $C$, James T, Trivedi P. Adaption of a technique for the accelerated aging of weed seeds to evaluate their longevity. N Z Plant Protect-SE. 2012;65:69-73.

3. Finch-Savage WE, Bassel GW. Seed vigour and crop establishment: extending performance beyond adaptation. J Exp Bot. 2016;67(3):567-91.

4. Company T, Soriano P, Estrelles E, Mayoral O. Seed bank longevity and germination ecology of invasive and native grass species from Mediterranean wetlands. Folia Geobot. 2019;54(1):151-61.

5. Pereira Lima JJ, Buitink J, Lalanne D, Rossi RF, Silva EAA, et al. Molecular characterization of the acquisition of longevity during seed maturation in soybean. PLoS ONE. 2017;12(7):e0180282.

6. Sallon S, Solowey E, Cohen Y, Korchinsky R, Egli M, Woodhatch I, Simchoni O, Kislev M. Germination, genetics, and growth of an ancient date seed. Science. 2008:320(5882):1464.

7. Bewley JD, Bradford K, Hilhorst H, Nonogaki H. Seeds. Physiology of development, germination and dormancy. 3rd ed. Berlin: Springer; 2013.

8. Hay FR, Valdez R, Lee JS, Sta Cruz PC. Seed longevity phenotyping: recommendations on research methodology. J Exp Bot. 2019;70(2):425-34.

9. Rajjou L, Debeaujon I. Seed longevity: survival and maintenance of high germination ability of dry seeds. C R Biol. 2008;331(10):796-805.

10. Long RL, Panetta FD, Steadman KJ, Probert RJ, Bekker RM, Brooks S, Adkins SW. Seed persistence in the field may be predicted by laboratorycontrolled aging. Weed Sci. 2008;56(4):523-8.

11. McDonald MB. Seed deterioration: physiology, repair and assessment. Seed Sci Technol. 1999;27(1):177-237.

12. Powell AA, Don R, Haigh P, Phillips G, Tonkin JHB, Wheaton OE. Assessment of the repeatability of the controlled deterioration test both within and between laboratories. Seed Sci Technol. 1984;12:421-7.

13. Powell AA, Matthews S. Towards the validation of the controlled deterioration vigour test for small-seeded vegetables. Seed Test Int. 2005;129:21-4.

14. Delouche JC, Baskin CC. Accelerated aging techniques for predicting the relative storability of seed lots. Seed Sci Technol. 1973;1:427-52.

15. Hampton JG, Tekrony DM. Handbook of vigour test methods. Zurich: The International Seed Testing Association; 1995.

16. Walters $C$, Hill LM, Wheeler LJ. Dying while dry: kinetics and mechanisms of deterioration in desiccated organisms. Integr Comp Biol. 2005:45(5):751-8.

17. Marcos-Filho J. Seed physiology of cultivated plants. 2nd ed. Londrina: ABRATES; 2015.

18. Hay FR, Whitehouse KJ. Rethinking the approach to viability monitoring in seed genebanks. Conserv Physiol. 2017;5(1):9.

19. Newton R, Hay F, Probert R. Protocol for comparative seed longevity testing. In: Technical information Sheet_01. Millennium Seed Bank Partnership, Royal Botanic Gardens, Kew. 2014.

20. Maier DS. Should biodiversity and nature have to earn their keep? What it really means to bring environmental goods into the marketplace. Ambio. 2018;47(4):477-92.

21. Faith D. Biodiversity's option value: a comment on Maier. Ambio. 2018;47(6):735-6. 
22. Maier DS. Response to "Biodiversity's option value: a comment on Maier (2018)" by Faith. Ambio. 2018;47(6):737-8.

23. Gioria M, Pyšek P. The legacy of plant invasions: changes in the soil seed bank of invaded plant communities. BioSci. 2016;66(1):40-53.

24. Intergovernmental Science-Policy Platform on Biodiversity and Ecosystem Services. Global assessment report on biodiversity and ecosystem services, IPBES. 2019.

25. Vilà M, Valladares F, Traveset A, Santamaría L, Castro P, editors. Invasiones Biológicas. Madrid: CSIC y Catarata; 2008.

26. Mudimba TN, Nguta JM. Traditional uses, phytochemistry and pharmacological activity of Carpobrotus edulis: a global perspective. J Phytopharmacol. 2019;8(3):111-6.

27. Vilà M, Tessier M, Suehs CM, Brundu G, Carta L, Galanidis A, et al. Local and regional assessments of the impacts of plant invaders on vegetation structure and soil properties of Mediterranean islands. J Biogeogr. 2006;33(5):853-61.

28. Vieites-Blanco C, González-Prieto SJ. Effects of Carpobrotus edulis invasion on soil gross $\mathrm{N}$ fluxes in rocky coastal habitats. Sci Total Environ. 2018;619-620:966-76.

29. Novoa A, González L. Impacts of Carpobrotus edulis (L.) NE Br. on the germination, establishment and survival of native plants: a clue for assessing its competitive strength. PLoS ONE. 2013;9(9):e107557.

30. Chenot J, Affre L, Passeti A, Buisson E. Consequences of iceplant (Carpobrotus) invasions on the vegetation and seed bank structure on a Mediterranean island: response elements for their local eradication. Acta Bot Gallica. 2014;161(3):301-8

31. Cacho OJ, Spring D, Pheloung P, Hester S. Evaluating the feasibility of eradicating an invasion. Biol Invasions. 2006;8(4):903-17.

32. Panetta FD, Cacho O, Hester S, Sims-Chilton N, Brooks S. Estimating and influencing the duration of weed eradication programmes. J Appl Ecol. 2011:48(4):980-8.

33. Bailly C. Active oxygen species and antioxidants in seed biology. Seed Sci Res. 2004;14(2):93-107.

34. Kibinza S, Vinel D, Côme D, Bailly C, Corbineau F. Sunflower seed deterioration as related to moisture content during aging, energy metabolism and active oxygen species scavenging. Physiol Plantarum. 2006;128(3):496-506.

35. Lehner A, Mamadou N, Poels P, Côme D, Bailly C, Corbineau F. Changes in soluble carbohydrates, lipid peroxidation and antioxidant enzyme activities in the embryo during aging in wheat grains. J Cereal Sci. 2008;47(3):555-65.

36. Yao Z, Liu L, Gao F, Rampitsch C, Reinecke DM, Ozga JA, et al. Developmental and seed aging mediated regulation of antioxidative genes and differential expression of proteins during pre- and postgerminative phases in pea. J Plant Physiol. 2012;169(15):1477-88.

37. Morscher F, Kranner I, Arc E, Bailly C, Roach T. Glutathione redox state, tocochromanols, fatty acids, antioxidant enzymes and protein carbonylation in sunflower seed embryos associated with after-ripening and aging. Ann Bot. 2015;116(4):669-78.

38. Zhou W, Chen F, Luo X, Dai Y, Yang Y, Zheng C, et al. A matter of life and death: molecular, physiological, and environmental regulation of seed longevity. Plant, Cell Environ. 2020;43(2):293-302.

39. Luna B, Moreno JM, Cruz A, Fernández-González F. Heat-shock and seed germination of a group of Mediterranean plant species growing in a burned area: an approach based on plant functional types. Environ Exp Bot. 2007;60(3):324-33.

40. Jaureguiberry P, Díaz S. Post-burning regeneration of the Chaco seasonally dry forest: germination response of dominant species to experimental heat shock. Oecologia. 2015;177(3):689-99.

41. Fichino BS, Dombroski JRG, Pivello VR, Fidelis A. Does fire trigger seed germination in the neotropical savannas? experimental tests with six Cerrado species. Biotropica. 2016;48(2):181-7.

42. Daws MI, Kabadajic A, Manger K, Kranner I. Extreme thermo-tolerance in seeds of desert succulents is related to maximum annual temperature. S Afr J Bot. 2007;73(2):262-5.
43. Whitaker C, Berjak P, Kolberg H, Pammenter N. Responses to various manipulations, and storage potential, of seeds of the unique desert gymnosperm, Welwitschia mirabilis Hook. fil. S Afr J Bot. 2004;70(4):622-30.

44. Suresh A, Shah N, Kotecha M, Robin P. Effect of natural, accelerated and saturated salt accelerated aging on the Jatropha curcas L. seeds in optimizing the yield of seed oil as feedstock for biodiesel. Energ Source Part A. 2019;41(8):990-1004.

45. Mira S, Veiga-Barbosa L, Pérez-García F. Seed dormancy and longevity variability of Hirschfeldia incana L. during storage. Seed Sci Res. 2019;29(2):97-103.

46. Wettlaufer SH, Leopold AC. Relevance of Amadori and Maillard products to seed deterioration. Plant Physiol. 1991;97(1):165-9.

47. Fu YB, Ahmed Z, Diederichsen A. Towards a better monitoring of seed aging under ex situ seed conservation. Conserv Physiol. 2015;3(1):Cov026.

48. Yuan $X$, Wen B. Seed germination response to high temperature and water stress in three invasive Asteraceae weeds from Xishuangbanna, SW China. PLoS ONE. 2018;13(1):e0191710.

49. Zani D, Müller JV. Climatic control of seed longevity of Silene during the post-zygotic phase: do seeds from warm, dry climates possess higher maturity and desiccation tolerance than seeds from cold, wet climates? Ecol Res. 2017;32(6):983-94

50. Fenollosa E, Munné-Bosch S, Pintó-Marijuan M. Contrasting phenotypic plasticity in the photoprotective strategies of the invasive species Carpobrotus edulis and the coexisting native species Crithmum maritimum. Physiol Plantarum. 2016;160(2):185-200.

51. Xu L, Lin Y, Wang L, Zhou YC. Dehiscence method: a seed-saving, quick and simple viability assessment in rice. Plant Methods. 2018;14:68.

52. Elias SG, Copeland LO, MCDonald MB, Baalbaki RZ. Seed testing-principles and practices. East Lansing: Michigan State University Press; 2012.

53. Kranner I, Minibayeva FV, Beckett RP, Seal CE. What is stress? Concepts, definitions and applications in seed science. New Phytol. 2010;188(3):655-73.

54. Cohen O, Riov J, Katan J, Gamliel A, Bar P. Reducing persistent seed banks of invasive plants by soil solarization-The case of Acacia saligna. Weed Sci. 2008;56(6):860-5.

55. Cohen O, Gamliel A, Katan J, Kurzbaum E, Riov J, Bar P. Controlling the seed bank of the invasive plant Acacia saligna: comparison of the efficacy of prescribed burning, soil solarization, and their combination. Biol Invasions. 2018;20(10):2875-87.

56. Cohen O, Bar P, Gamliel A, Katan J, Kurzbaum E, Weber G, Schubert I, Riov J. Rain-based soil solarization for reducing the persistent seed banks of invasive plants in natural ecosystems-Acacia saligna as a model. Pest Manag Sci. 2019;75(7):1933-41.

57. Daws MI, Burslem DFRP, Crabtree LM, Kirkman P, Mullins CE, Dalling JW. Differences in seed germination responses may promote coexistence of four sympatric Piper species. Funct Ecol. 2002;16(2):258-67.

58. Hadley N. Micrometeorology and energy exchange in two desert arthropods. Ecology. 1970;51(3):434-44.

59. Patil VN, Dadlani M. Tetrazolium test for seed viability and vigour. In: Handbook of seed testing, 2009. pp. 209-41.

60. Novoa A, González L, Moravcová L, Pyšek P. Constraints to native plant species establishment in coastal dune communities invaded by Carpobrotus edulis: implications for restoration. Biol Conserv. 2013:164:1-9.

61. Podda L, Santo A, Mattana E, Mayoral O, Bacchetta G. Inter-and intravariability of seed germination traits of Carpobrotus edulis $\mathrm{NE} \mathrm{Br}$. and its hybrid C. affine acinaciformis. Plant Biol. 2018;20(6):1059-67.

62. Ritz C, Baty F, Streibig JC, Gerhard D. Dose-response analysis using R. PLoS ONE. 2015;10(12):e0146021.

\section{Publisher's Note}

Springer Nature remains neutral with regard to jurisdictional claims in published maps and institutional affiliations. 